\title{
Vehicle Security Tracker
}

\author{
Durga Prasad Singh \\ B-Tech in Computer Science \& Engineering \\ Diploma in Computer Science \& Engineering
}

\begin{abstract}
Vehicle Security Tracker (VST Tracker) is a tracker system for the security of vehicle which helps us to enhance the security level of stopped and moving vehicle at any point of location and time to facilitate the safe and secure journey to the peoples of the country. We also are willing to supply emergency support to the peoples like Medical, Police, Maintenance and other necessary support. It is basically meant for the purpose of Emergency support in the lonely areas and highways and to find crimes and the criminal held on the road and highways as soon as possible which helps innocent peoples to save their life from the fake and unwanted cases and to find stolen or missing vehicle and criminal soon.
\end{abstract}

VST Tracker is small and effective tracking device working with the help of GSM network with the mobile SIM Technology to track by Mobile number or SIM number or IMEI number but the major challenges is that NO single Mobile network cover the whole area of country, so that we can enable the roaming facilities of the SIM so that it can directly change over the other network quickly for better service. VST Tracker define the voice calling facilities to the user to connect data centre to communicate and ask for emergency support and compliant just by one click and within 10-15 sec. The Components of the VST Tracker is similar to the mobile phone like SIM Slot, Battery, Mobile Chipset, Mic and others but it not content keypad, camera, Speaker and many more. It is just develop for the purpose of tracking and calling only.

VST Tracker is beneficial for both personal use as well as Transportation use to make pollution and Crime free and other illegal activities. It help to supply of goods and Product and services at right time and at right place It also help peoples to make up-to date of their vehicle papers and documents with low budget and safe, secure and easy environment to run their life and vehicle smoothly. Other benefit of VST Tracker is to track the stolen vehicle soon and to find out the right criminal from the crime as a Crime Case Solving Device and most important Secure Travel (FOR VIP) who need extra security to travel wherever in country.

\section{Keywords}

SIM, IMEI, GSM, IMSI, MEI

\section{INTRODUCTION}

Vehicle Security Tracker (VST Tracker) is a tracker system for the security of vehicle which help us to enhance the security level of stopped and moving vehicle at any point of location and time to facilitate the safe and secure journey to the peoples of the country. we also willing to provide emergency support to the peoples like Medical, Police, Maintenance and other necessary support. It is basically meant for the purpose of Emergency support in the lonely areas and highways and to find crimes and the criminal held on the road and highways as soon as possible which helps innocent peoples to save their life from the fake and unwanted cases and to find stolen or missing vehicle and criminal soon. VST Tracker helps the peoples to track their family members and relatives cars in case of delay or not reached the destination in proper time duration with the help of Police case.

VST Tracker helps the peoples to track their family members and relatives cars in case of delay or not reached the destination in proper time duartion.VST also allow to track the thief of car and location of both.VST Tracker systems also help the peoples to maintain and make up to date of their documents and services of the vehicle by sending him/her a update message for the same and provide better support and services for the same.

VST Tracker define the secure travel by the help of network and it enable the pushup bottom to click once and directly connected with Data Centre Customer Care and ask for any type of Emergency support then automatically call will connect to user and pick up after 3-5 Sec and Speaker of vehicle is used for hearing and pushup Mic is for talking and query for the support if they didn't respond to the call for 10$15 \mathrm{Sec}$ after calling then it assume that anything happened so directly inform to nearest Police and Medical will reach their as soon as possible.

VST Tracker is small and effective tracking device working with the help of GSM network with the mobile SIM Technology to track by Mobile number or SIM number or IMEI number but the major challenges is that NO single Mobile network cover the whole area of country, so that we can enable the roaming facilities of the SIM so that it can directly change over the other network quickly for better service. VST Tracker define the voice calling facilities to the user to connect data centre to communicate and ask for emergency support and compliant just by one click and within 10-15 sec. The Components of the VST Tracker is similar to the mobile phone like SIM Slot, Battery, Mobile Chipset, Mic and others but it not content keypad, camera, Speaker and many more. It is just develop for the purpose of tracking and calling only.

\section{PROBLEM AND NEED DEFINITIONS}

With the help of Today's scenario, Now a days we heard the many news from the news channels that there was some vehicle stolen case and made the crime with thaw stolen vehicle and innocent owner get trap in that crime, and also heard that there are some vehicle and owner both are missing from last many days and finally we got the dead body of the person in his car and the case was running from last so many years and also that there are many vehicles got accident on road and the original criminal get escape from there and innocent person got caught for that crime and send to the jail which result that the person after completing the punishment he/ she will become new criminal in the area because he/she will have no fear of laws and police now. Sometimes we are waiting for our family members and relatives but unfortunately they meet with an accident and we don't know regarding that accident. Many times we found that the person who meet with the accident can be live if the treat will done on right time but they don't get that due to no one knows about that accident and when we got to know at that time they will dead. normally we person travel their phone are gone out of coverage area and no one able to connect and contact him to share and take information and status of him/her. Our aim 
to provide the better secure and safe journey to the people of country.

Problems which are facing by the peoples is that no safe way to travel and fear to involved in the fake and any illegal activities which destroy him/her life and sometime they will lost his/her life due to criminal effects and incidents by vehicle on roads .

\section{IDENTITY, KEY FUNCTIONS \&}

\section{ALERT}

\subsection{Ignition Alert}

Ignition Alert is an alert which is used by the VST Tracker agent to start tracking the vehicle. It define that the vehicle is started and location where it started. We can use it in both personal and transportation as well. It also indicate that the device starts charging and vehicle directly come to the tracker list to be track.

\subsection{Distance Alert}

Distance Alert is an alert or report made by VST Tracker agent and send to Users in form of pdf. It define the distance report of vehicle that how much distance it travelled and how much distance it has to be travel and also which route it have to be followed. Distance alert report are generated as per User request on daily, weekly basis, monthly basis, vehicle wise, trip wise, and other criteria as per the user.

\subsection{Over Speed Alert}

Over speed alert is an alert made by VST tracker agent and send a alert message to End User and Clients. It is basically for Transportation use but also we provide this services for personal use on demand for the purpose of secure and safe journey of families. If anyone found to be very high speed in market and crowded area then he/she will give the reason for the high-speed else necessary action will taken.

\subsection{Insurance Alert}

Insurance Alert is an alert made by VST Tracker agent and send to the End User and Clients. It defines for the purpose of making up to date of vehicle papers and documents. It gives alert message regarding Insurance expiry and renew dates before one month of the last date of expiry and also help to find the better and low budget insurance farm/corporation near by the users.

\subsection{Usage Alert}

Usage Alert is an alert made by the VST Tracker agent and send to the Client and Data Center Manager. Basically it develops for the transportation use. It alerts when any person force to driver to drive the vehicle continuously more than the limited hours for the client. It helps the End User to be free from fatigue and pressure and increase employment.

\subsection{Maintenance Alert}

Maintenance Alert is an alert made by VST Tracker agent and send to the End User and Clients. It define for the purpose of making maintained and pollution free vehicle and Environment. It gives alert message regarding Maintenance date and KMS and nearest service center for the Service before 10-15 days of the last date and as per KMS. It designs for both Personal as well as Transportation Use.

\subsection{Safety Alert}

Safety Alert is an alert which define for the purpose of safety of vehicle. It send a alert message to the End User and Clients, if the vehicle change it location without ignition alert or any tracking process and also help to track the vehicle if case of stolen by the thief and reported complain by the Users to the Police Station.

Our aim to trace the stolen vehicle and thief as soon as possible and help in decrease the vehicle stolen case and crime made by stolen vehicles.

\subsection{Due / Undue Alert}

Due / Undue Alert is an alert made by the VST Tracker agent to send a message to the clients. It define for the purpose of delivery services right time to the right destination and also find the reason of delay and delay location and time. It shows the complete graphical view of the vehicle that from where it start and where it reached and how many stoppage is due/remain too reached. Clients \& End -User request for the alert then agent made the report and send by mail or message.

\subsection{Reached Alert}

Reached Alert is an alert message send by the VST Tracker agent to the Clients whenever and wherever is required. It defines to give acknowledgment to the Clients that goods and product was reached to your destination kindly check it ASAP.

\subsection{Up-To-Date Documents}

Up-to-Date documents meant for the purpose of the making legal and secure of all papers and related documents up to date. So User able to live and drive their vehicle secure and without tension of any vehicle problems and crimes. This is done by the both means of communication voice and mail.

\subsection{Track Stolen Vehicle}

This is built for the purpose of finding and tracking the stolen or missing vehicle and catch the criminal and save the victim and solve the case of missing and stolen vehicle as soon as possible and other similar crimes that can be done by that vehicle or other. On the basis of spot location and longitude disturbance or changes of the vehicle position and it help security and police department of caught the criminal before any crime happened and also help in find right criminal for punishment.

\subsection{Secure Travel}

Secure travel meant for VIP Persons and any important guests. Secure Travel defines for the purpose of the security concern of VIP's. If it required to run a secure travel then our executives are continuously tracking the path and vehicles running with the rally. If unauthorized and any illegal activities found on or in between the route then urgently inform to the nearby police and the security guard also to be alert for the action which may be occurred. It also helps to track the criminals to catch then as soon as possible.

\subsection{Emergency Support}

Emergency Support is not an alert, It is a support. It defines for the purpose of the Emergency help needed in between the journey and any other situation. Emergency Support declare almost all the field like Hospitality, Police, Maintenance, and many more by just one click. In case of accident or robbery or other dangerous condition then both medical as well as police reached there and save the life of peoples of our country.

\section{HARDWARE AND SOFTWARE USED 4.1. Use of Device Hardware}

In this hardware, it combines with all components like SIM Slot, Battery, and Mobile chipset with external Mic and other necessary parts. All parts are assemble in compact device and the Mic is fix on the front of desk or near music systems or others. This approach works similar to the mobile device with 
the best in guidance of Mobile and Network Companies. Hardware is fix in the car in that manner so no one can break and remove the device if it remove or damage it send a alert signal to the Operator.

\subsection{Use of Tracking Software}

Tracking software use to track the vehicle and spot the current location and act immediately when anyone needs emergency support. On a tracking system the output come only in excel format of Device UID, Vehicle name and current time \& Location and emergency support (If Any). In case of Emergency support it give details of nearby medical, police and maintenance as per his/her current location by the tracker.

\section{PURPOSED ALGORITHM}

Step 0 -

Initially Vehicle is in Stopped or Standby status to the home or office or anywhere else. It means vehicle does not moved anywhere to anywhere.

Step 1 - Key insert to start the car and Ignition system of the car started which allow device to start charging which help us determine that vehicle start travel or moving.

Step 2 -

Vehicle directly come to the tracking list from the stop \& standby list and it update the status of vehicle and be in tracking queue.

Step 3 - In tracking list, Vehicle start updating the location and time in interval of 3-5 sec. if the vehicle stop in any location more than $5 \mathrm{~min}$ it automatically come to the Stop \& Standby list (It meant that person reached destination safely.)

Step 4 - If any person stop and travel again and again between interval of 15- 20 min than it automatically come from standby to tracking list again and again for secure and safe journey.

Step 5 - While travelling if any incident happen in between the source and destination or you need any emergency supports then just click the Mic bottom twice else we assume that you are safe.

Step 6 - If YES (Anything Happen) then tell to the agent on call which are connected by clicking the Mic Button and ask for support whichever you required at that location and at that time too.

Listen the type of support demand by you and we contact to that support centre nearby to you and send them as soon as possible to help you and your family.
Step 7 -

Step 8 - Type of supports that we are provide or supply for your better safe and secure journey are Hospitability, Police, Maintenance and other local helps as per need on demand of peoples in future.

Step 9 - Finally in both case YES or NO, you reached your destination safe and secure by the use of the emergency support or by not use of this and you enjoy the services and life too.

We add more steps in future extension of the project to enhance the more security and safe journey of peoples of country.

\section{CONCLUSION}

Vehicle Security Tracker main aim to enhance and track the security level of vehicle with the help of Mobile GSM Network and to provide emergency support of peoples of country It track the vehicle using mobile network and enable the calling for the necessary emergency support like medical, police, maintenance and other if you needed in lonely and alone area location and it also used for the Isecure travel for the VIP person or guest who visit our country with high priority of security.VST Tracker also help to enhance the police functioning and road transportation of country and all people will follow the law, rules and regulations of Transportations of country.

\section{REFERENCES}

[1] http://en.wikipedia.org/wiki/GSM

[2] http://en.wikipedia.org/wiki/Subscriber_identity_module.

[3] http://en.wikipedia.org/wiki/International_mobile_subscr iber_identity

[4] http://en.wikipedia.org/wiki/Mobile_phone

[5] http://en.wikipedia.org/wiki/Mobile_equipment_identifie

[6] http://en.wikipedia.org/wiki/International_Mobile_Statio n_Equipment_Identity 